\title{
Metagenomic Identification of Viral Sequences in Laboratory Reagents
}

\author{
Ashleigh F. Porter ${ }^{1}$, Joanna Cobbin ${ }^{2,3}, \mathrm{Ci}-\mathrm{Xiu} \mathrm{Li}^{4}{ }^{4}$, John-Sebastian Eden ${ }^{2,3,5}$ and Edward C. Holmes ${ }^{2,3, * \mathbb{C}}$ \\ 1 The Peter Doherty Institute of Immunity and Infection, Department of Microbiology and Immunity, \\ University of Melbourne, Melbourne, VIC 3000, Australia; ashleigh.porter@unimelb.edu.au \\ 2 Sydney Institute for Infectious Diseases, School of Life and Environmental Sciences, The University of Sydney, \\ Sydney, NSW 2006, Australia; joanna.cobbin@sydney.edu.au (J.C.); js.eden@sydney.edu.au (J.-S.E.) \\ 3 Sydney Institute for Infectious Diseases, School of Medical Sciences, The University of Sydney, \\ Sydney, NSW 2006, Australia \\ 4 Key Laboratory of Etiology and Epidemiology of Emerging Infectious Diseases in Universities of Shandong, \\ Shandong First Medical University \& Shandong Academy of Medical Sciences, Taian 271000, China; \\ cixiu.li@sydney.edu.au \\ 5 Centre for Virus Research, Westmead Institute for Medical Research, Westmead, NSW 2145, Australia \\ * Correspondence: edward.holmes@sydney.edu.au
}

Citation: Porter, A.F.; Cobbin, J.; Li, C.-X.; Eden, J.-S.; Holmes, E.C. Metagenomic Identification of Viral Sequences in Laboratory Reagents. Viruses 2021, 13, 2122. https:/ / doi.org/10.3390/v13112122

Academic Editor: Subir Sarker

Received: 12 September 2021

Accepted: 19 October 2021

Published: 21 October 2021

Publisher's Note: MDPI stays neutral with regard to jurisdictional claims in published maps and institutional affiliations.

Copyright: (c) 2021 by the authors. Licensee MDPI, Basel, Switzerland. This article is an open access article distributed under the terms and conditions of the Creative Commons Attribution (CC BY) license (https:// creativecommons.org/licenses/by/ $4.0 /)$.

\begin{abstract}
Metagenomic next-generation sequencing has transformed the discovery and diagnosis of infectious disease, with the power to characterise the complete 'infectome' (bacteria, viruses, fungi, parasites) of an individual host organism. However, the identification of novel pathogens has been complicated by widespread microbial contamination in commonly used laboratory reagents. Using total RNA sequencing ("metatranscriptomics") we documented the presence of contaminant viral sequences in multiple 'blank' negative control sequencing libraries that comprise a sterile water and reagent mix. Accordingly, we identified 14 viral sequences in 7 negative control sequencing libraries. As in previous studies, several circular replication-associated protein encoding (CRESS) DNA virus-like sequences were recovered in the blank control libraries, as well as contaminating sequences from the Totiviridae, Tombusviridae and Lentiviridae families of RNA virus. These data suggest that viral contamination of common laboratory reagents is likely commonplace and can comprise a wide variety of viruses.
\end{abstract}

Keywords: reagent contamination; virology; metatranscriptomics; Circoviridae; Totiviridae; Tombusviridae; Lentiviridae

\section{Introduction}

Culture-independent methods, particularly metagenomic next-generation sequencing (mNGS), have revolutionised pathogen discovery, streamlined pathways of clinical diagnosis, and have enhanced our ability to track infectious disease outbreaks [1], including the current COVID-19 pandemic [2,3]. These methods can reveal the complete profile of pathogenic and commensal microorganisms within a host, comprising viruses, bacteria, fungi and eukaryotic parasites. As mNGS, particularly total RNA sequencing (i.e., metatranscriptomics), enables the identification of diverse and divergent viral sequences, it has been widely utilised for virus discovery [4-8].

Although the data generated by mNGS are bountiful and cost-effective, they come with several inherent limitations, central of which is the possibility of reagent contamination [9]. Indeed, the contamination of $\mathrm{mNGS}$ data can be problematic when identifying microbes in the context of disease association and creates issues when attempting to identify the true host of a novel microbe. The experimental preparation of samples for sequencing necessarily involves treatment with a variety of reagents, many of which have been shown to carry contaminating nucleic acids, including viral sequences [10-15]. Previous work has illuminated the extent of viral contamination in commonly used laboratory components, 
particularly those with small single-stranded (ss) DNA genomes [9,14,16-18]. Accordingly, there is a clear need for appropriate controls when characterising novel viruses from metagenomic data. For example, metagenomic analysis of human plasma samples revealed the presence of sequences of Kadipiro virus, a double-stranded positive-sense RNA virus [19], although these were later shown to likely reflect contamination [20]. An additional complication is that reagent-associated viral sequences are often not shared nor widespread across samples, only appearing intermittently [9].

Although mNGS has identified many novel viruses, diverse species of circular replicationassociated protein encoding (CRESS) ssDNA viruses have been particularly prominent [21-25]. However, as noted above, ssDNA viruses, particularly CRESS viruses and their relatives including circoviruses, are common contaminants of reagents, leading to incorrect inferences on host associations $[9,26]$. As well as DNA viruses, a variety of other microbial sequences are present in laboratory reagents, including bacteria, RNA viruses, and eukaryotic parasites $[9,20,27-30]$.

To further explore the diversity of contaminant sequences in laboratory components, particularly those derived from viruses, we used metatranscriptomics to investigate seven libraries of blank RNA sequencing samples that represent sterile water extractions and library preparation reagents.

\section{Materials and Methods}

\subsection{Generating 'Blank' Sequencing Libraries}

When generating total RNA sequencing libraries, we regularly utilise negative or 'blank' samples as experimental controls to assess the extent of reagent contamination. These controls are derived from extractions of the sterile water used at the elution step and, importantly, are expected to contain no nucleic acid material. In theory, these negative controls should generate no sequencing reads. However, they can capture contamination during the DNA/RNA extraction or library preparation steps.

Herein, we analysed negative control sequencing libraries under different experimental conditions to identify likely contaminant sequences (Table 1). Total RNA was extracted using either the RNeasy Plus Universal Kit (Qiagen, Hilden, Germany), RNeasy Plus Mini Kit (Qiagen, Hilden, Germany) or the Total RNA purification Kit (Norgen BioTek Corp., Thorold, ON, Canada), as described in Table 1. RNA libraries were prepared with the Trio RNA-seq + UDI Library Preparation Kit (NuGEN) or the SMARTer Stranded Total RNA-Seq Kit v2-Pico Input Mammalian (Takara Bio, USA) and sequenced on the MiSeq, NextSeq or NovaSeq Illumina platforms, producing between $0.63 \mathrm{~Gb}$ and $8.7 \mathrm{~Gb}$ of data per library.

Table 1. Experimental conditions of each blank negative control sample utilised here.

\begin{tabular}{|c|c|c|c|c|c|}
\hline Library Name & Sequencing Platform & RNA Extraction & $\begin{array}{c}\text { Library } \\
\text { Preparation }\end{array}$ & Data Generated & $\begin{array}{c}\text { SRA Library } \\
\text { Accession }\end{array}$ \\
\hline L1 & $\begin{array}{l}\text { Illumina Novaseq } 6000 \\
150 \text { cycle kit } \\
(2 \times 75 \text { nt reads })\end{array}$ & $\begin{array}{l}\text { RNeasy Plus } \\
\text { Universal Kits } \\
\text { (Qiagen, Hilden, } \\
\text { Germany) }\end{array}$ & $\begin{array}{l}\text { Trio RNA-seq + } \\
\text { UDI (NuGEN) }\end{array}$ & $\begin{array}{l}11,940,824 \text { paired } \\
\text { reads }(1.8 \mathrm{~Gb})\end{array}$ & SRR14737471 \\
\hline L2 & $\begin{array}{c}\text { Illumina Novaseq } 6000 \\
150 \text { cycle kit } \\
(2 \times 75 \text { nt reads })\end{array}$ & $\begin{array}{l}\text { RNeasy Plus } \\
\text { Universal Kits } \\
\text { (Qiagen, Hilden, } \\
\text { Germany) }\end{array}$ & $\begin{array}{l}\text { Trio RNA-seq + } \\
\text { UDI (NuGEN) }\end{array}$ & $\begin{array}{l}57,606,392 \text { paired } \\
\quad \text { reads }(8.7 \mathrm{~Gb})\end{array}$ & SRR14737470 \\
\hline L3 & $\begin{array}{l}\text { Illumina MiSeq, v3 } \\
150 \text { cycle kit } \\
(2 \times 75 \text { nt reads })\end{array}$ & $\begin{array}{l}\text { RNeasy Plus Mini } \\
\text { Kit (Qiagen, } \\
\text { Hilden, Germany) }\end{array}$ & $\begin{array}{l}\text { SMARTer Stranded } \\
\text { Total RNA-Seq Kit } \\
\text { v2 -Pico Input } \\
\text { Mammalian } \\
\text { (Clontech) }\end{array}$ & $\begin{array}{c}4,156,504 \text { paired } \\
\text { reads }(0.63 \mathrm{~Gb})\end{array}$ & SRR10069984 \\
\hline
\end{tabular}


Table 1. Cont.

\begin{tabular}{|c|c|c|c|c|c|}
\hline Library Name & Sequencing Platform & RNA Extraction & $\begin{array}{c}\text { Library } \\
\text { Preparation }\end{array}$ & Data Generated & $\begin{array}{l}\text { SRA Library } \\
\text { Accession }\end{array}$ \\
\hline L4 & $\begin{array}{l}\text { Illumina NextSeq 500, } \\
\text { mid-output } 150 \text { cycle } \\
\text { kit }(2 \times 75 \text { nt reads })\end{array}$ & $\begin{array}{c}\text { Total RNA } \\
\text { Purification Kit } \\
\text { (Norgen Biotek, } \\
\text { Thorold, ON, } \\
\text { Canada) }\end{array}$ & $\begin{array}{l}\text { SMARTer Stranded } \\
\text { Total RNA-Seq Kit } \\
\text { v2-Pico Input } \\
\text { Mammalian } \\
\text { (Clontech) }\end{array}$ & $\begin{array}{c}32,279,914 \text { paired } \\
\text { reads }(4.91 \mathrm{~Gb})\end{array}$ & SRR14737469 \\
\hline L5 & $\begin{array}{l}\text { Illumina MiSeq } \\
150 \text { cycle kit } \\
(2 \times 75 \text { nt reads })\end{array}$ & $\begin{array}{c}\text { Total RNA } \\
\text { purification Kit } \\
\text { (Norgen BioTek } \\
\text { Corp., Thorold, } \\
\text { ON, Canada) }\end{array}$ & $\begin{array}{l}\text { SMARTer Stranded } \\
\text { Total RNA-Seq Kit } \\
\text { v2-Pico Input } \\
\text { Mammalian } \\
\text { (Clontech) }\end{array}$ & $\begin{array}{c}7,342,876 \text { paired } \\
\text { reads } \\
(1.10 \mathrm{~Gb})\end{array}$ & SRR15221433 \\
\hline L6 & $\begin{array}{l}\text { Illumina MiSeq } \\
150 \text { cycle kit } \\
(2 \times 75 \text { nt reads })\end{array}$ & $\begin{array}{c}\text { Total RNA } \\
\text { purification Kit } \\
\text { (Norgen BioTek } \\
\text { Corp., Thorold, } \\
\text { ON, Canada) }\end{array}$ & $\begin{array}{l}\text { SMARTer Stranded } \\
\text { Total RNA-Seq Kit } \\
\text { v2-Pico Input } \\
\text { Mammalian } \\
\text { (Clontech) }\end{array}$ & $\begin{array}{c}10,978,253 \\
\text { paired reads } \\
(1.65 \mathrm{~Gb})\end{array}$ & SRR15221432 \\
\hline L7 & $\begin{array}{l}\text { Illumina MiSeq } \\
150 \text { cycle kit } \\
(2 \times 75 \text { nt reads })\end{array}$ & $\begin{array}{c}\text { Total RNA } \\
\text { purification Kit } \\
\text { (Norgen BioTek } \\
\text { Corp., Thorold, } \\
\text { ON, Canada) }\end{array}$ & $\begin{array}{l}\text { SMARTer Stranded } \\
\text { Total RNA-Seq Kit } \\
\text { v2-Pico Input } \\
\text { Mammalian } \\
\text { (Clontech) }\end{array}$ & $\begin{array}{c}8,564,269 \\
1.28 \mathrm{~Gb}\end{array}$ & SRR14737466 \\
\hline
\end{tabular}

\subsection{Analysis of Virus-Like Sequences in Laboratory Reagents}

Each sequencing library underwent trimming and the de novo assembly of reads, completed using the Trinity software with default settings [31] or MEGAHIT (L3) [32]. Sequence similarity searches using Diamond BLASTX were performed on the de novo assembled contigs against the GenBank non-redundant (nr) database [33,34]. Specifically, we used a combination of e-value, hit length, and percentage similarity to determine the potential of a contig to be a viral sequence. The abundance of reagent-associated reads was calculated by comparing the number of contig reads to the total number of library reads (via mapping trimmed reads back to the contigs) as performed in previous studies [5,8].

After initial identification, all potential contaminant sequences were subjected to phylogenetic analysis. To ensure high quality amino acid sequence alignments, only conserved sequence contigs that were $>800 \mathrm{bp}$ ( $>200$ amino acids) in length were used in downstream analysis. Sequences of reference proteins, including the highly conserved replicase, DNA polymerase and RNA-dependent RNA polymerase (RdRp) protein domains, were downloaded from the NCBI RefSeq database (Table 2). Contig and reference proteins were aligned using the L-INS-I algorithm in MAFFT v7 [35], with ambiguously aligned regions removed using Gblocks [36]. This resulted in final sequence alignments of between 125 and 672 amino acids in length (Table 2). Phylogenetic trees of all alignments were then estimated using the maximum likelihood method in IQ-TREE [37], using the model testing option and bootstrap resampling with 500 replications.

Table 2. Reference proteins for each sequence alignment performed in this analysis.

\begin{tabular}{ccccc}
\hline Reference Protein & $\begin{array}{c}\text { Protein } \\
\text { Acronym }\end{array}$ & $\begin{array}{c}\text { Virus } \\
\text { Taxonomy }\end{array}$ & $\begin{array}{c}\text { Number of Sequences } \\
\text { in Analysis }\end{array}$ & $\begin{array}{c}\text { Alignment Length } \\
\text { (Amino Acid, AA) }\end{array}$ \\
\hline Viral replicase protein & Rep & CRESS & 221 & 672 AA \\
\hline Viral replicase protein & Rep & Circoviridae & 69 & 161 AA \\
\hline Polymerase peptide & Pol & Lentiviridae & 11 & 478 AA \\
\hline RNA-dependent RNA polymerase & RdRp & Totiviridae & 95 & 125 AA \\
\hline RNA-dependent RNA polymerase & RdRp & Tombusviridae & 87 & 256 AA \\
\hline
\end{tabular}




\section{Results}

In total, we identified 14 reagent-associated viral sequences in the negative (blank) control samples, including seven CRESS-like viral sequences, four novel Tombusviridae-like viral sequences, and single Lentivirus-like and Totiviridae-like viral sequences.

\subsection{Abundance of Reagent-Associated Viral Reads}

The abundance of reads in each library was calculated to compare the percentage of reads associated with viruses (Figure 1). This revealed that the virus-associated contigs identified were predominantly CRESS-like (Figure 1). The L5 library contained only one virus-associated contig, associated with Escherichia coli phage PhiX 174 DNA: this was intentionally added into the sequencing run to add complexity and improve signal in the library. Both the L4 and L6 libraries did not contain long ( $>800 \mathrm{bp}$ ) virus-associated contigs.
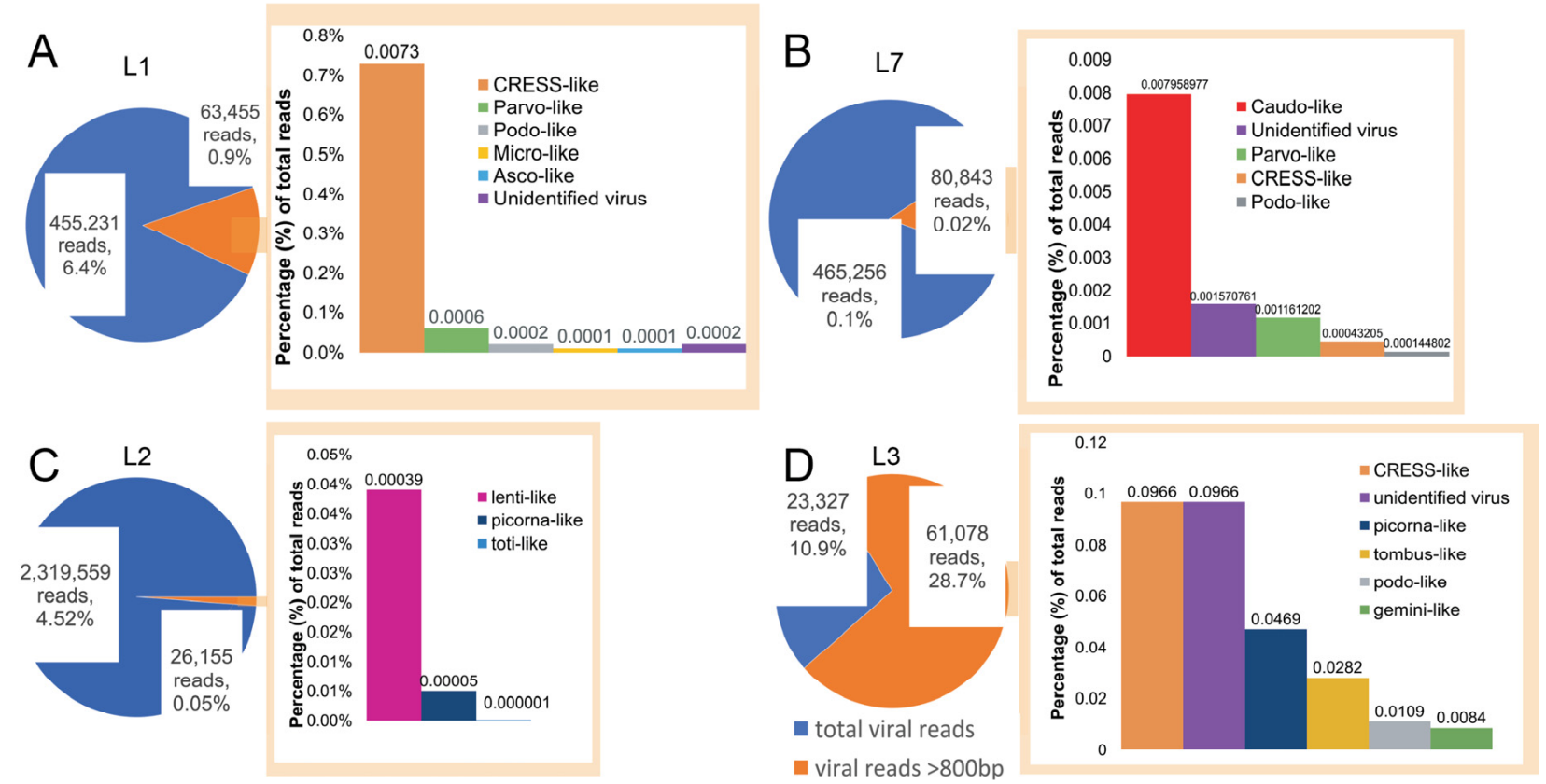

Figure 1. Abundance of viral reads in libraries L1, L2, L3, and L7. Visual representation of the virus-associated reads in respective libraries, with pie charts depicting the total number reads mapped to long ( $>800 \mathrm{bp}$ ) virus-associated contigs (orange) compared to all the virus-associated reads (blue). (A-D) Each bar chart denotes the proportion of contigs associated with different virus families in the respective libraries.

Novel reagent-associated virus-like sequences were identified in four of the seven libraries (Table 3). Seven novel circo-like viruses (termed Reagent-associated CRESS-like virus 1-7), four novel tombusvirus-like viruses (termed Reagent-associated tombus-like virus 1-4), and one totivirus-like and lentivirus-like sequence (termed Reagent-associated toti-like virus and Reagent-associated lenti-like virus, respectively) were identified in libraries L1, L2 and L3. The contigs ranged from 828 to 3878 bp in length and comprised $0.0001-1.27 \%$ of reads in their associated libraries.

Table 3. Novel reagent-associated viral sequences identified in this study.

\begin{tabular}{ccccc}
\hline Virus name & \multirow{2}{*}{ Accession } & $\begin{array}{c}\text { Library Abundance (\%) of } \\
\text { Total Reads (rRNA Removed) }\end{array}$ & Length (bp) & Library \\
\hline Reagent-associated tombus-like virus 1 & MZ824229 & 1.28 & 1204 & L3 \\
Reagent-associated tombus-like virus 2 & MZ824228 & 0.46 & 828 & L3 \\
Reagent-associated tombus-like virus 3 & MZ824227 & 1.08 & 1574 & L3 \\
Reagent-associated tombus-like virus 4 & MZ824226 & 1.29 & 1410 & L3 \\
\hline
\end{tabular}


Table 3. Cont.

\begin{tabular}{ccccc}
\hline Virus name & Accession & $\begin{array}{c}\text { Library Abundance (\%) of } \\
\text { Total Reads (rRNA Removed) }\end{array}$ & Length (bp) & Library \\
\hline Reagent-associated toti-like virus & MZ824225 & 0.001 & 920 & L2 \\
Reagent-associated lenti-like virus & MZ824230 & 0.004 & 962 & L2 \\
Reagent-associated CRESS-like virus 1 & MZ824237 & 0.78 & 3878 & L1 \\
Reagent-associated CRESS-like virus 2 & MZ824236 & 0.24 & 2377 & L1 \\
Reagent-associated CRESS-like virus 3 & MZ824235 & 0.02 & L1 \\
Reagent-associated CRESS-like virus 4 & MZ824234 & 2.89 & 2663 & L3 \\
Reagent-associated CRESS-like virus 5 & MZ824233 & 9.66 & 3027 & L3 \\
Reagent-associated CRESS-like virus 6 & MZ824232 & 4.98 & 3517 & L3 \\
Reagent-associated CRESS-like virus 7 & MZ824231 & 0.01 & L1 \\
\hline
\end{tabular}

\subsection{Characterisation of Reagent-Associated Circovirus-Like and CRESS-Like Viruses}

Due to extensive genetic diversity within the Circoviridae we inferred two separate sequence alignments and hence two phylogenetic trees, representing the (i) CRESS and CRESS-like viruses and (ii) circoviruses taken independently, although both were based on the Rep protein sequence (Figures 2 and 3). All seven of the novel reagent-associated circovirus-like sequences exhibited greater sequence similarity to the CRESS viruses and therefore were included in the CRESS virus phylogeny. These were termed Reagentassociated CRESS-like viruses 1-7. These viruses occupied diverse locations across the phylogeny, although they were closely related to some previously identified reagentassociated viruses: Avon-Heathcote estuary associated circular viruses, Circoviridae sp. subtypes, Dromedary stool-associated circular virus subtypes, and Sandworm circovirus [5,9] (Figure 2). It is notable that the CRESS viruses analysed derive from a variety of environments, and there is no clear topological pattern according to the host species of sample origin, which is anticipated in the case of contaminant sequences. The seven novel CRESSlike viruses identified also varied in abundance in the L1 and L3 libraries (0.01-9.66\%). In contrast, a phylogenetic analysis of the Rep protein of other members of Circoviridae (Table 2), containing what we hypothesise are bona fide viruses, reveals a pattern of hostbased clustering (Figure 3). In particular, this phylogeny was characterised by two distinct clades of circoviruses: circoviruses, associated with vertebrate hosts, and cycloviruses associated with invertebrates.

\subsection{Characterisation of Reagent-Associated Lentivirus-Like, Tombusvirus-Like and Totivirus-Like Sequences}

Aside from ssDNA viruses, we identified an additional seven novel reagent-associated viral sequences in the blank control libraries. The first of these was a novel lentiviruslike sequence that we then used in an alignment of the retroviral Pol protein (Table 2). A phylogenetic tree was inferred from the alignment and the novel Reagent-associated lenti-like virus was shown to cluster closely with Equine infectious anaemia viruses (EIAV), although occupying a relatively long branch within this clade (Figure 4).

Similarly, we identified four novel tombus-like sequences in the blank control samples: these were termed Reagent-associated tombus-like virus 1-4. A sequence alignment of the RdRp protein domain was used to infer a phylogenetic tree of these tombusviruslike sequences that are commonly associated with plants (Table 2). Three of the novel tombus-like viruses cluster together in the same divergent clade that falls basal to a majority of the tombus-like viruses (Figure 5). Only two previously described tombus-like virus sequences fall in more divergent positions-Wenzhou tombus-like virus 11 and Sclerotinia sclerotiorum umbra-like virus 1 . As these were both identified in metatranscriptomic studies $[8,38]$ it is possible that they reflect reagent contamination, although Sclerotinia sclerotiorum umbra-like virus 1 was found in two samples of Sclerotinia sclerotiorum (a fungus) compatible with its status as a true mycovirus [38,39]. Interestingly, Plasmopara viticola lesion associated tombus-like virus 2 , also suggested to be a mycovirus, similarly 
falls into a relatively divergent clade (Figure 5). Finally, Reagent-associated tombus-like virus 3 was identified in blank library L3 at a relatively high abundance $(>1 \%$ of total reads), although it had a shorter (1574 bp) and likely incomplete genome compared to most tombusviruses $(\sim 4-5 \mathrm{~kb})$. This sequence falls basal to a clade within the broader tombusvirus tree that includes a variety of plant viruses, including Groundnut rosette virus, Carrot mottle virus and Tobacco mottle virus.
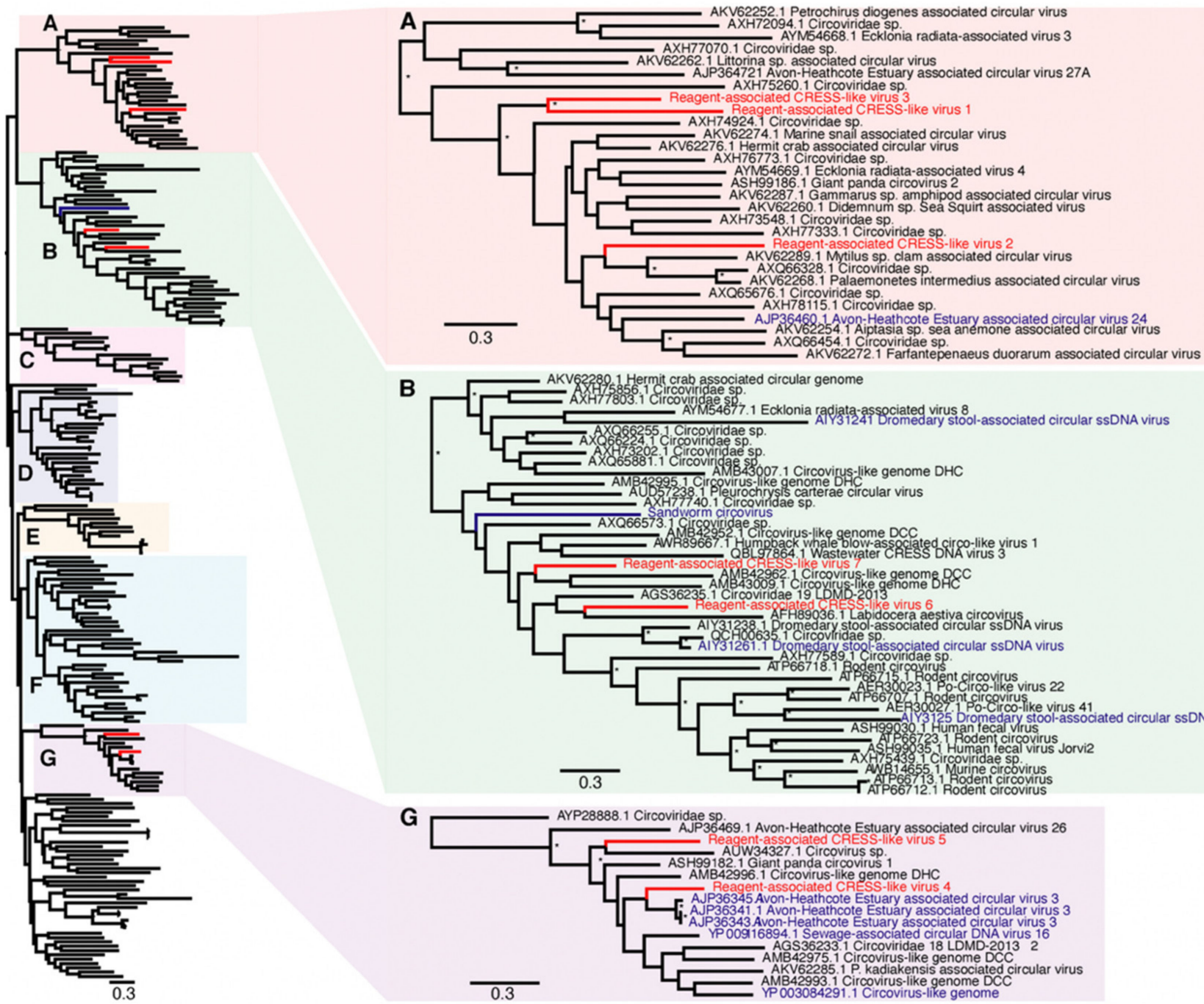

B
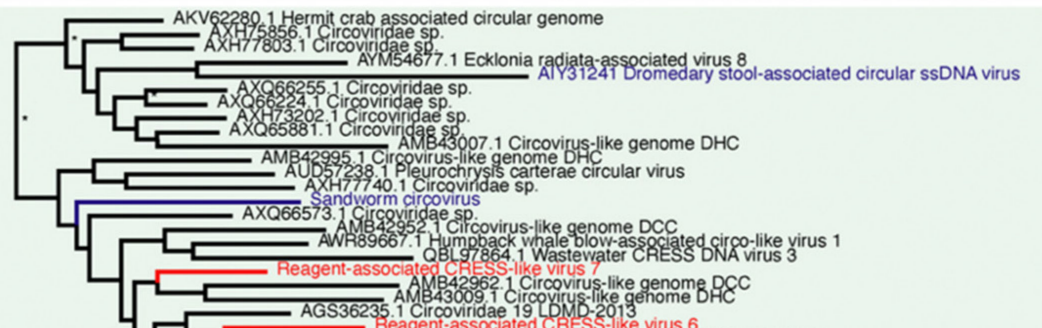

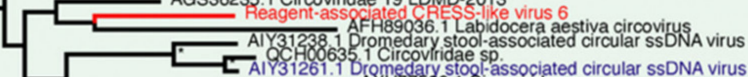
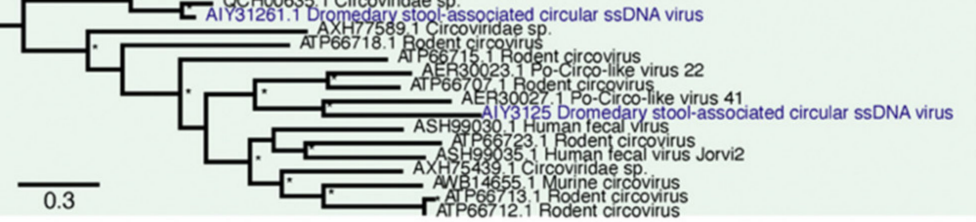

G AYP28888.1 Circoviridae $\mathrm{Sp}$.JPP 369.1 Avon-Heathcote Estuary associated circular virus 26

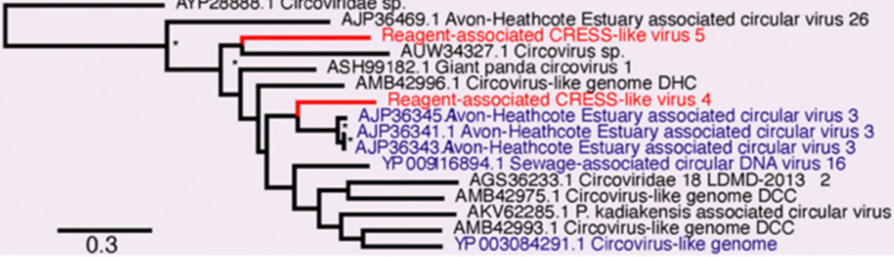

Figure 2. Phylogenetic relationships of CRESS (ssDNA) viruses, including the seven novel CRESS-like viruses identified here and highlighted in red (Reagent-associated CRESS-like viruses 1-7). Reagent-associated sequences determined previously are highlighted in blue. The clades that included the novel CRESS-like viruses identified here $(\mathbf{A}, \mathbf{B}, \mathbf{G})$ are magnified on the right. The tree and other clades (C-F) are shown in higher resolution in Supplementary Figure S1. The tree was mid-point rooted for clarity purposes only. Bootstrap values greater than $70 \%$ are represented by asterisks next to nodes. All horizontal branch lengths are scaled according to the number of amino acid substitutions per site. 


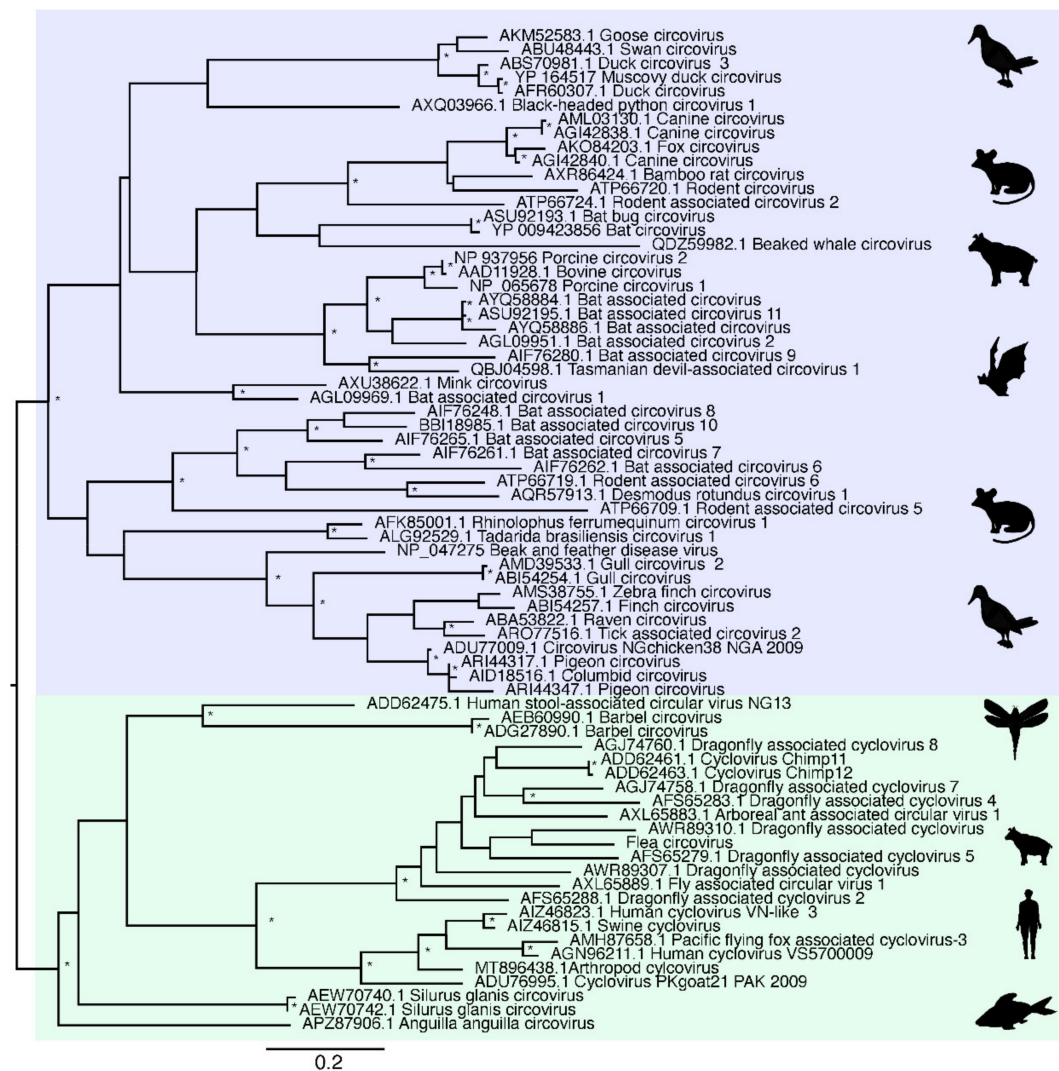

Figure 3. Phylogenetic relationships of the ssDNA virus family Circoviridae based on hypothesised "host-associated" circoviruses. The tree has two major clades, comprising the circovirus clade associated with vertebrate hosts (highlighted in blue) and the cyclovirus clade previously associated with invertebrate hosts (highlighted in green). For clarity, the tree is mid-point rooted. Bootstrap values greater than $70 \%$ are represented by asterisks next to nodes. All horizontal branch lengths are scaled according to number of amino acid substitutions per site.

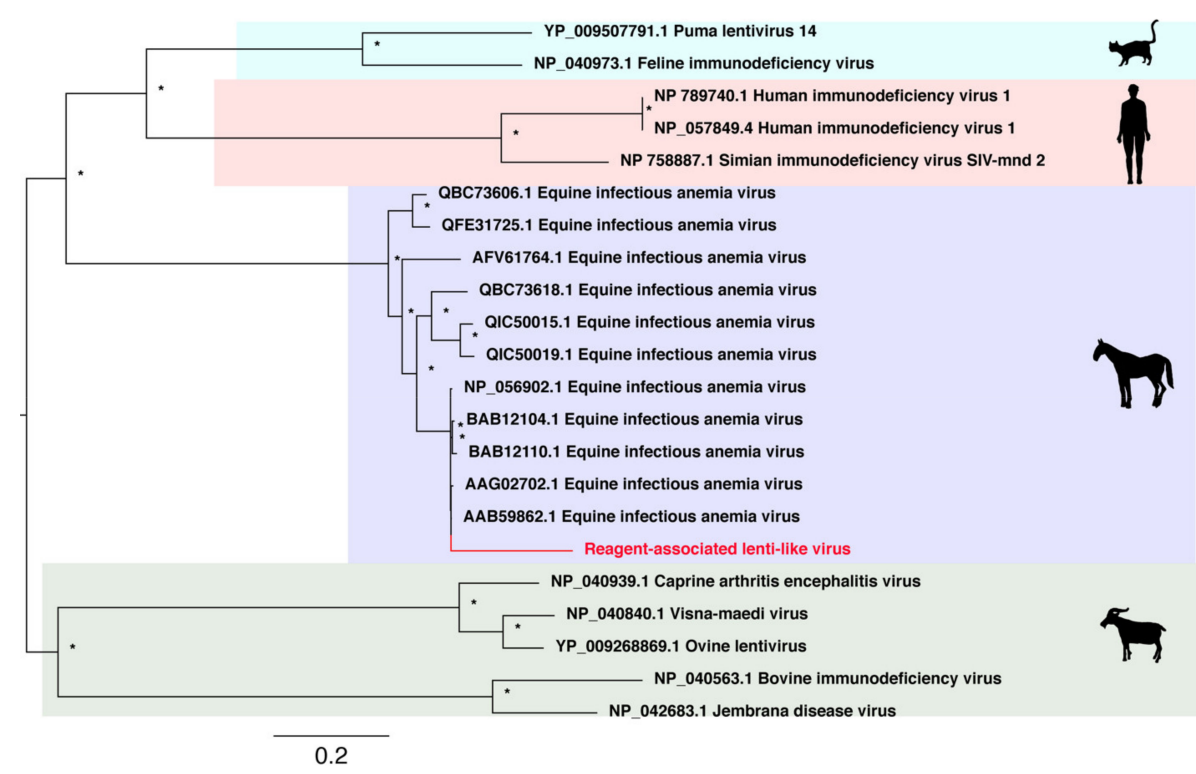

Figure 4. Phylogenetic relationships of RNA virus family Lentiviridae including the novel virus reagent-associated lenti-like virus sequence identified in this study. This virus is highlighted in red and falls within the EIAV clade. 


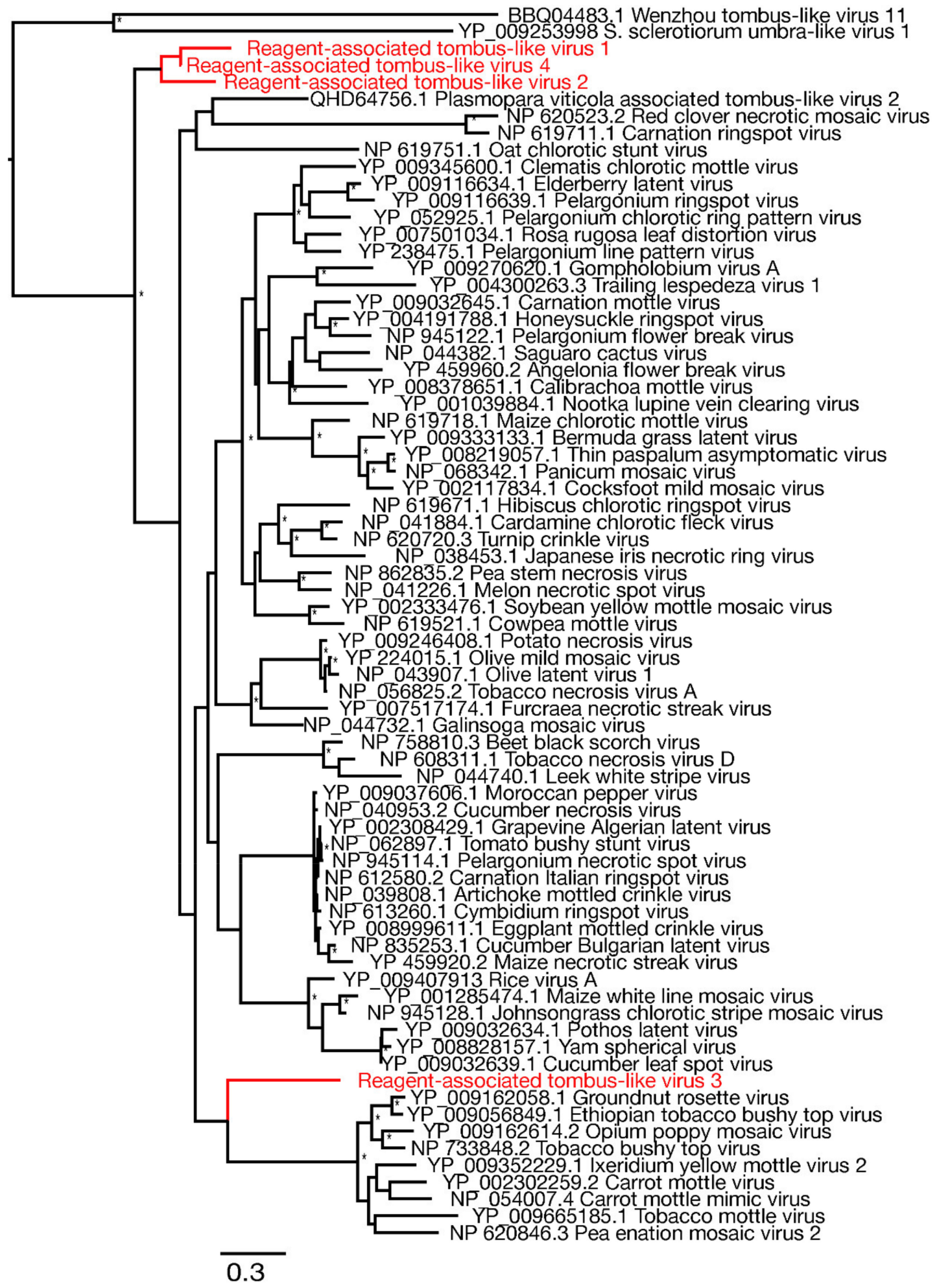

Figure 5. Phylogenetic relationships of RNA virus family Tombusviridae including the seven novel viruses identified in this study (highlighted in red). The phylogeny was mid-point rooted for clarity purposes only. Bootstrap values greater than $70 \%$ are represented by asterisks next to nodes. All horizontal branch lengths are scaled according to number of amino acid substitutions per site.

Finally, the remaining novel sequence was related to the totiviruses, a family of doublestrand RNA viruses commonly associated with fungi. The novel totivirus-like sequence was termed Reagent-associated toti-like virus. It was used in an alignment of the RdRp 
protein domain (Table 2), from which a phylogenetic tree was estimated (Figure 6). This revealed that the sequence appears to be related to Scheffersomyces segobiensis virus (83\% amino acid identity) associated with the fungus Scheffersomyces segobiensis.

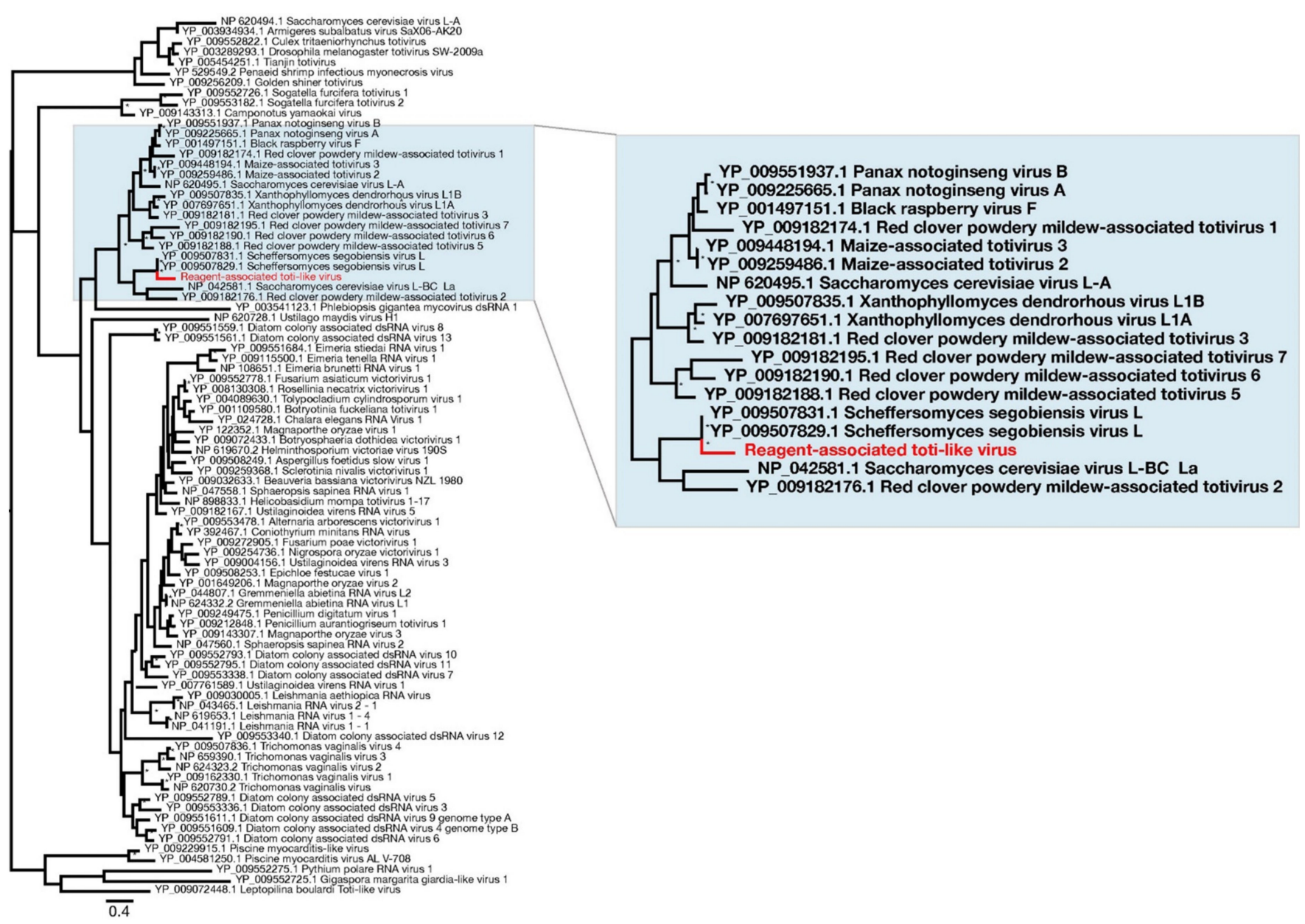

Figure 6. Phylogenetic relationships of RNA virus family Totiviridae, including the novel virus identified in this study-Reagent-associated toti-like virus (highlighted in red). For clarity, the tree was mid-point rooted. Bootstrap values greater than $70 \%$ are represented by asterisks next to nodes. All horizontal branch lengths are scaled according to number of amino acid substitutions per site.

\section{Discussion}

Viral sequences, particularly those with single-stranded DNA genomes, have previously been associated with common laboratory components [9], and these contaminant viral sequences have sometimes led to erroneous disease associations [14,17,18,20,40]. Herein, using a series of blank controls comprising sterile water and commonly used laboratory reagents, we identified a diverse range of viral sequences.

Few laboratory reagents appear to be entirely free from contamination, particularly by ssDNA viruses and predominantly circoviruses $[5,9,26]$. Indeed, approximately half of the viral sequences identified here were CRESS-like members of the Circoviridae. Unfortunately, high levels of sequence diversity prevented us from obtaining a meaningful alignment of the Rep protein for the novel CRESS-like virus sequences obtained here and known Circoviridae. Accordingly, we divided the family into sub-groups, denoted here as "hostassociated circoviruses" (Figure 3) and "CRESS and CRESS-like viruses" and performed phylogenetic analyses on each (Figure 2). Notably, in the "host-associated circovirus" phylogeny viruses generally clustered according to the broad host species of origin. In contrast, within the CRESS and CRESS-like phylogeny, clades could not be defined based on specific hosts or environments, and while many samples were originally derived from marine- or 
faeces-associated environments, these sequences did not cluster together. Interestingly, however, one of viruses identified in this study, Reagent-associated CRESS-like virus 4, was most closely related to Avon-Heathcote Estuary associated circular virus 3, previously identified as a reagent-associated virus [41]. In addition, the seven novel CRESS-like sequences identified here were related to previously identified reagent-associated viruses, including those identified by Asplund et al. (highlighted in blue, Figure 2) [9], as well as Sandworm circovirus similarly proposed to be a reagent contaminant [42]. This strongly suggests that these sequences are likely associated with laboratory reagents.

It is therefore clear that CRESS-like viruses are common experimental reagent contaminants, with widespread reagent-associated sequences dispersed throughout the CRESS phylogeny. This, along with the range of CRESS viruses of undetermined host origin, create major difficulties in determining the origin of novel CRESS viruses. Although there have been many new members of Circoviridae characterised in recent years, particularly cycloviruses $[5,43,44]$, we suggest that current and future characterisations of novel circovirusand CRESS-like genomes should be completed cautiously with additional confirmation steps. A review of the current members of Circoviridae is also advisable as these likely include viruses with contaminant origins but incorrectly assigned to a specific host organism. As a case in point, multiple cycloviruses are listed as having vertebrate hosts (such as Human cyclovirus VS5700009) even though these viruses are normally associated with invertebrates.

We also identified several tombusvirus-like sequences in this study, as well as a totivirus- and lentivirus-like sequence. The Tombusviridae are a family of single-strand positive-sense RNA viruses which are usually associated with mosaic diseases in plants. We identified four novel tombusvirus-like sequences associated with laboratory reagents, calling into question the provenance of other novel tombusviruses identified in some meta-transcriptomic studies [45]. The identification of reagent-associated tombusviruslike sequences suggests that additional care should be taken when characterising novel tombusvirus sequences, particularly when associating novel or previously identified tombusviruses with a host or disease. Similarly, although the natural hosts of the Totiviridae are fungi, other Totiviridae are associated with human-infecting protozoa, such as Trichomonasvirus associated with Trichomonas vaginalis [46] and Giardiavirus that likely infects Giardia lamblia protozoa [47,48]. The novel Reagent-associated totivirus identified in this study is distantly related to known totiviruses. We recommend that caution be taken when identifying novel totiviruses, especially if they are related to reagent-associated toti-like virus.

Lentiviruses are a genus within the Retroviridae and are well documented in a wide range of vertebrate species. The novel sequence identified in this study - reagent-associated lenti-like virus-is closely related to several known sequences of equine infectious anemia virus (EIAV) that cause the chronic disease, equine infectious anaemia (EIA) in horses. EIAV is transmissible through bodily secretions [49,50], and has been suggested to be vector-borne through biting flies [51]. Although the novel reagent-associated lenti-like virus was genetically distinct from known EIAV sequences, care should obviously be taken to ensure that any EIAV-like virus is a true viral infection rather than a reagent contaminant.

\section{Conclusions}

This study further highlights the extent of viral sequences in commonly used laboratory reagents [9] and the power of mNGS to monitor contamination in microbiological laboratories [52]. Although the source of these contaminants is unknown and needs further scrutiny, we tentatively suggest that viral vectors (for example, in the Lentiviridae) represent a likely source. Factors to consider when assessing the presence of reagent contaminants include genome coverage, read depth and distribution of read alignments across genomes, and that potential contaminant sequences are often only present at low abundance and in multiple libraries. Importantly, reagent-associated viruses are often more prevalent in sequencing reads than assembled contigs, emphasising the importance of careful assess- 
ment when relying on read data alone for characterising novel viruses and other microbial genomes $[9,26]$. Interestingly, most viral reads identified were in L1-L3, all of which were generated using the RNeasy Plus Mini Kit (Qiagen, Hilden, Germany).

Finally, our work highlights the importance of employing additional steps such as PCR or cell culture to confirm the presence of the pathogen after initial metagenomic identification $[9,26]$. Clearly, sequencing negative controls, such as that using sterile water and reagent mix as performed here, should become normal procedure in quality control.

Supplementary Materials: The following are available online at https: / www.mdpi.com/article/10 .3390/v13112122/s1, Figure S1: Phylogenetic relationships of CRESS viruses, including the seven novel CRESS-like viruses identified in this study.

Author Contributions: Conceptualisation, E.C.H.; methodology, A.F.P., J.C., C.-X.L. and J.-S.E.; formal analysis, A.F.P.; writing-original draft preparation, A.F.P. and E.C.H.; writing-review and editing, A.F.P., E.C.H., C.-X.L., J.C., J.-S.E.; funding acquisition, E.C.H. All authors have read and agreed to the published version of the manuscript.

Funding: This research was funded by an Australian Research Council Australian Laureate Fellowship to E.C.H (grant FL170100022).

Institutional Review Board Statement: Not applicable.

Informed Consent Statement: Not applicable.

Data Availability Statement: The viral genome sequence data generated in this study have been deposited in the NCBI database under accession numbers MZ824225-37. Sequence reads are available at the public Sequence Read Archive (SRA) database with accession SRX6803604 and under the BioProject accession PRJNA735051 reference numbers SRR14737466-71 and BioSample numbers SAMN20355437-40.

Acknowledgments: We acknowledge the University of Sydney high performance computing cluster Artemis and Sydney Informatics Hub, which was used for the analyses in this study.

Conflicts of Interest: The authors declare no conflict of interest.

\section{References}

1. Grubaugh, N.D.; Ladner, J.T.; Lemey, P.; Pybus, O.G.; Rambaut, A.; Holmes, E.C.; Andersen, K.G. Tracking virus outbreaks in the twenty-first century. Nat. Microbiol. 2019, 4, 10-19. [CrossRef] [PubMed]

2. Lu, R.; Zhao, X.; Li, J.; Niu, P.; Yang, B.; Wu, H.; Wang, W.; Song, H.; Huang, B.; Zhu, N.; et al. Genomic characterisation and epidemiology of 2019 novel coronavirus: Implications for virus origins and receptor binding. The Lancet 2020, 395, 565-574. [CrossRef]

3. Gudbjartsson, D.F.; Helgason, A.; Jonsson, H.; Magnusson, O.T.; Melsted, P.; Norddahl, G.L.; Saemundsdottir, J.; Sigurdsson, A.; Sulem, P.; Agustsdottir, A.B.; et al. Spread of SARS-CoV-2 in the Icelandic population. N. Engl. J. Med. 2020, 382, $2302-2315$. [CrossRef]

4. Zhang, Y.-Z.; Chen, Y.-M.; Wang, W.; Qin, X.-C.; Holmes, E.C. Expanding the RNA virosphere by unbiased metagenomics. Annu. Rev. Virol. 2019, 6, 119-139. [CrossRef]

5. Porter, A.F.; Pettersson, J.H.O.; Chang, W.-S.; Harvey, E.; Rose, K.; Shi, M.; Eden, J.-S.; Buchmann, J.; Moritz, C.; Holmes, E.C. Novel hepaci- and pegi-like viruses in native Australian wildlife and non-human primates. Virus Evol. 2020, 6, veaa064. [CrossRef]

6. Geoghegan, J.L.; Di Giallonardo, F.; Cousins, K.; Shi, M.; Williamson, J.E.; Holmes, E.C. Hidden diversity and evolution of viruses in market fish. Virus Evol. 2018, 4, vey031. [CrossRef]

7. Harvey, E.; Rose, K.; Eden, J.S.; Lo, N.; Abeyasuriya, T.; Shi, M.; Doggett, S.L.; Holmes, E.C. Extensive diversity of RNA viruses in Australian ticks. J. Virol. 2019, 93, e01358-18. [CrossRef]

8. Shi, M.; Lin, X.D.; Tian, J.H.; Chen, L.J.; Chen, X.; Li, C.X.; Qin, X.C.; Li, J.; Cao, J.P.; Eden, J.S.; et al. Redefining the invertebrate RNA virosphere. Nature 2016, 540, 539-543. [CrossRef]

9. Asplund, M.; Kjartansdóttir, K.R.; Mollerup, S.; Vinner, L.; Fridholm, H.; Herrera, J.A.; Friis-Nielsen, J.; Hansen, T.A.; Jensen, R.H.; Nielsen, I.B. Contaminating viral sequences in high-throughput sequencing viromics: A linkage study of 700 sequencing libraries. Clin. Microbiol. Infect. 2019, 25, 1277-1285. [CrossRef]

10. Kjartansdóttir, K.R.; Friis-Nielsen, J.; Asplund, M.; Mollerup, S.; Mourier, T.; Jensen, R.H.; Hansen, T.A.; Rey-Iglesia, A.; Richter, S.R.; Alquezar-Planas, D.E.; et al. Traces of ATCV-1 associated with laboratory component contamination. Proc. Natl. Acad. Sci. USA 2015, 112, E925-E926. [CrossRef] 
11. Laurence, M.; Hatzis, C.; Brash, D.E. Common contaminants in next-generation sequencing that hinder discovery of lowabundance microbes. PLoS ONE 2014, 9, e97876. [CrossRef]

12. Friis-Nielsen, J.; Kjartansdóttir, K.R.; Mollerup, S.; Asplund, M.; Mourier, T.; Jensen, R.H.; Hansen, T.A.; Rey-Iglesia, A.; Richter, S.R.; Nielsen, I.B. Identification of known and novel recurrent viral sequences in data from multiple patients and multiple cancers. Viruses 2016, 8, 53. [CrossRef]

13. Lysholm, F.; Wetterbom, A.; Lindau, C.; Darban, H.; Bjerkner, A.; Fahlander, K.; Lindberg, A.M.; Persson, B.; Allander, T.; Andersson, B. Characterization of the viral microbiome in patients with severe lower respiratory tract infections using metagenomic sequencing. PLoS ONE 2012, 7, e30875. [CrossRef]

14. Smuts, H.; Kew, M.; Khan, A.; Korsman, S. Novel hybrid parvovirus-like virus, NIH-CQV/PHV, contaminants in silica columnbased nucleic acid extraction kits. J. Virol. 2014, 88, 1398. [CrossRef]

15. Lusk, R.W. Diverse and widespread contamination evident in the unmapped depths of high throughput sequencing data. PLoS ONE 2014, 9, e110808.

16. Knox, K.; Carrigan, D.; Simmons, G.; Teque, F.; Zhou, Y.; Hackett, J.; Qiu, X.; Luk, K.-C.; Schochetman, G.; Knox, A. No evidence of murine-like gammaretroviruses in CFS patients previously identified as XMRV-infected. Science 2011, 333, 94-97. [CrossRef]

17. Naccache, S.N.; Greninger, A.L.; Lee, D.; Coffey, L.L.; Phan, T.; Rein-Weston, A.; Aronsohn, A.; Hackett, J.; Delwart, E.L.; Chiu, C.Y. The perils of pathogen discovery: Origin of a novel parvovirus-like hybrid genome traced to nucleic acid extraction spin columns. J. Virol. 2013, 87, 11966-11977. [CrossRef]

18. Paprotka, T.; Delviks-Frankenberry, K.A.; Cingöz, O.; Martinez, A.; Kung, H.-J.; Tepper, C.G.; Hu, W.-S.; Fivash, M.J.; Coffin, J.M.; Pathak, V.K. Recombinant origin of the retrovirus XMRV. Science 2011, 333, 97-101. [CrossRef] [PubMed]

19. Ngoi, C.N.; Siqueira, J.; Li, L.; Deng, X.; Mugo, P.; Graham, S.M.; Price, M.A.; Sanders, E.J.; Delwart, E. The plasma virome of febrile adult Kenyans shows frequent parvovirus B19 infections and a novel arbovirus (Kadipiro virus). J. Gen. Virol. 2016, 97, 3359-3367. [CrossRef] [PubMed]

20. Ngoi, C.N.; Siqueira, J.; Li, L.; Deng, X.; Mugo, P.; Graham, S.M.; Price, M.A.; Sanders, E.J.; Delwart, E. Corrigendum: The plasma virome of febrile adult Kenyans shows frequent parvovirus B19 infections and a novel arbovirus (Kadipiro virus). J. Gen. Virol. 2017, 98, 517. [CrossRef] [PubMed]

21. Kerr, M.; Rosario, K.; Baker, C.C.M.; Breitbart, M. Discovery of four novel circular single-stranded DNA viruses in fungus-farming termites. Microbiol. Res. Announc. 2018, 6, e00318-18. [CrossRef] [PubMed]

22. Kazlauskas, D.; Dayaram, A.; Kraberger, S.; Goldstien, S.; Varsani, A.; Krupovic, M. Evolutionary history of ssDNA bacilladnaviruses features horizontal acquisition of the capsid gene from ssRNA nodaviruses. Virology 2017, 504, 114-121. [CrossRef] [PubMed]

23. Krupovic, M.; Ghabrial, S.A.; Jiang, D.; Varsani, A. Genomoviridae: A new family of widespread single-stranded DNA viruses. Arch. Virol. 2016, 161, 2633-2643. [CrossRef] [PubMed]

24. Rosario, K.; Breitbart, M.; Harrach, B.; Segales, J.; Delwart, E.; Biagini, P.; Varsani, A. Revisiting the taxonomy of the family Circoviridae: Establishment of the genus Cyclovirus and removal of the genus Gyrovirus. Arch. Virol. 2017, 162, 1447-1463. [CrossRef]

25. Varsani, A.; Krupovic, M. Smacoviridae: A new family of animal-associated single-stranded DNA viruses. Arch. Virol. 2018, 163, 3213-3214. [CrossRef] [PubMed]

26. Holmes, E.C. Reagent contamination in viromics: All that glitters is not gold. Clin. Microbiol. Infect. 2019, 25, 1167-1168. [CrossRef]

27. De Goffau, M.C.; Lager, S.; Salter, S.J.; Wagner, J.; Kronbichler, A.; Charnock-Jones, D.S.; Peacock, S.J.; Smith, G.C.; Parkhill, J. Recognizing the reagent microbiome. Nat. Microbiol. 2018, 3, 851-853. [CrossRef] [PubMed]

28. Salter, S.J.; Cox, M.J.; Turek, E.M.; Calus, S.T.; Cookson, W.O.; Moffatt, M.F.; Turner, P.; Parkhill, J.; Loman, N.J.; Walker, A.W. Reagent and laboratory contamination can critically impact sequence-based microbiome analyses. BMC Biol. 2014, $12,87$. [CrossRef]

29. Zinter, M.; Mayday, M.; Ryckman, K.; Jelliffe-Pawlowski, L.; DeRisi, J. Towards precision quantification of contamination in metagenomic sequencing experiments. Microbiome 2019, 7, 62. [CrossRef]

30. Stinson, L.F.; Keelan, J.A.; Payne, M.S. Identification and removal of contaminating microbial DNA from PCR reagents: Impact on low-biomass microbiome analyses. Lett. Appl. Microbiol. 2019, 68, 2-8. [CrossRef]

31. Grabherr, M.G.; Haas, B.J.; Yassour, M.; Levin, J.Z.; Thompson, D.A.; Amit, I.; Adiconis, X.; Fan, L.; Raychowdhury, R.; Zeng, Q.; et al. Full-length transcriptome assembly from RNA-Seq data without a reference genome. Nat. Biotech. 2011, 29, 644-652. [CrossRef]

32. Li, D.; Liu, C.-M.; Luo, R.; Sadakane, K.; Lam, T.-W. MEGAHIT: An ultra-fast single-node solution for large and complex metagenomics assembly via succinct de Bruijn graph. Bioinformatics 2015, 31, 1674-1676. [CrossRef]

33. Buchfink, B.; Xie, C.; Huson, D.H. Fast and sensitive protein alignment using DIAMOND. Nat. Meth. 2015, 12, 59-60. [CrossRef]

34. Camacho, C.; Coulouris, G.; Avagyan, V.; Ma, N.; Papadopoulos, J.; Bealer, K.; Madden, T.L. BLAST+: Architecture and applications. BMC Bioinformatics 2009, 10, 421. [CrossRef]

35. Katoh, K.; Standley, D.M. MAFFT multiple sequence alignment software version 7: Improvements in performance and ssability. Mol. Biol. Evol. 2013, 30, 772-780. [CrossRef] 
36. Castresana, J. Selection of conserved blocks from multiple alignments for their use in phylogenetic analysis. Mol. Biol. Evol. 2000, 17, 540-555. [CrossRef]

37. Nguyen, L.-T.; Schmidt, H.A.; von Haeseler, A.; Minh, B.Q. IQ-TREE: A fast and effective stochastic algorithm for estimating maximum-likelihood phylogenies. Mol. Biol. Evol. 2015, 32, 268-274. [CrossRef]

38. Marzano, S.-Y.; Nelson, B.D.; Ajayi-Oyetunde, O.; Bradley, C.A.; Hughes, T.J.; Hartman, G.L.; Eastburn, D.M.; Domier, L.L. Identification of diverse mycoviruses through metatranscriptomics characterization of the viromes of five major fungal plant pathogens. J. Virol. 2016, 90, 6846-6863. [CrossRef]

39. Mu, F.; Xie, J.; Cheng, S.; You, M.P.; Barbetti, M.J.; Jia, J.; Wang, Q.; Cheng, J.; Fu, Y.; Chen, T.; et al. Virome characterization of a collection of S. sclerotiorum from Australia. Front. Microbiol. 2018, 8, 2540. [CrossRef] [PubMed]

40. Erlwein, O.; Robinson, M.J.; Dustan, S.; Weber, J.; Kaye, S.; McClure, M.O. DNA extraction columns contaminated with murine sequences. PLoS ONE 2011, 6, e23484. [CrossRef] [PubMed]

41. Dayaram, A.; Goldstien, S.; Arguello-Astorga, G.R.; Zawar-Reza, P.; Gomez, C.; Harding, J.S.; Varsani, A. Diverse small circular DNA viruses circulating amongst estuarine molluscs. Infect. Genet. Evol. 2015, 31, 284-295. [CrossRef]

42. Porter, A.F.; Shi, M.; Eden, J.-S.; Zhang, Y.-Z.; Holmes, E.C. Diversity and evolution of novel invertebrate DNA ciruses revealed by meta-transcriptomics. Viruses 2019, 11, 1092. [CrossRef] [PubMed]

43. Rosario, K.; Dayaram, A.; Marinov, M.; Ware, J.; Kraberger, S.; Stainton, D.; Breitbart, M.; Varsani, A. Diverse circular ssDNA viruses discovered in dragonflies (Odonata: Epiprocta). J. Gen. Virol. 2012, 93, 2668-2681. [CrossRef] [PubMed]

44. Islam, S.U.; Lin, W.; Wu, R.; Lin, C.; Islam, W.; Arif, M.; Du, Z.; Wu, Z. Complete genome sequences of three novel cycloviruses identified in a dragonfly (Odonata: Anisoptera) from China. Arch. Virol. 2018, 163, 2569-2573. [CrossRef]

45. Culley, A.I.; Lang, A.S.; Suttle, C.A. Metagenomic analysis of coastal RNA virus communities. Science 2006, 312, 1795-1798. [CrossRef]

46. Goodman, R.P.; Ghabrial, S.A.; Fichorova, R.N.; Nibert, M.L. Trichomonasvirus: A new genus of protozoan viruses in the family Totiviridae. Arch. Virol. 2011, 156, 171-179. [CrossRef]

47. Wang, A.L.; Yang, H.M.; Shen, K.A.; Wang, C.C. Giardiavirus double-stranded RNA genome encodes a capsid polypeptide and a gag-pol-like fusion protein by a translation frameshift. Proc. Natl. Acad. Sci. USA 1993, 90, 8595-8599. [CrossRef]

48. Wang, A.L.; Wang, C.C. Viruses of the protozoa. Annu. Rev. Microbiol. 1991, 45, 251-263. [CrossRef]

49. Sellon, D.C.; Fuller, F.J.; McGuire, T.C. The immunopathogenesis of equine infectious anemia virus. Virus Res. 1994, 32, 111-138. [CrossRef]

50. Issel, C.J.; Adams, W.V., Jr.; Meek, L.; Ochoa, R. Transmission of equine infectious anemia virus from horses without clinical signs of disease. J. Am. Vet. Med. Assoc. 1982, 180, 272-275.

51. Hawkins, J.A.; Adams, W.V., Jr.; Wilson, B.H.; Issel, C.J.; Roth, E.E. Transmission of equine infectious anemia virus by Tabanus fuscicostatus. J. Am. Vet. Med. Assoc. 1976, 168, 63-64. [PubMed]

52. Xiao, Y.; Zhang, L.; Yang, B.; Li, M.; Ren, L.; Wang, J. Application of next generation sequencing technology on contamination monitoring in microbiology laboratory. Biosaf. Health 2019, 1, 25-31. [CrossRef] [PubMed] 


\section{University Library}

\section{- M M I N E R VA A gateway to Melbourne's research publications}

Minerva Access is the Institutional Repository of The University of Melbourne

Author/s:

Porter, AF;Cobbin, J;Li, C-X;Eden, J-S;Holmes, EC

Title:

Metagenomic Identification of Viral Sequences in Laboratory Reagents

Date:

2021-11-01

Citation:

Porter, A. F., Cobbin, J., Li, C. -X., Eden, J. -S. \& Holmes, E. C. (2021). Metagenomic

Identification of Viral Sequences in Laboratory Reagents. VIRUSES-BASEL, 13 (11), https:// doi.org/10.3390/v13112122.

Persistent Link:

http://hdl.handle.net/11343/296583

License:

CC BY 